\title{
TEACHING AND LEARNING SUPPORT FOR STUDENTS WITH DISABILITIES: ISSUES AND PERSPECTIVES IN OPEN DISTANCE E-LEARNING
}

\author{
Dr. Sithabile NTOMBELA \\ ORCID: 0000-0003-4196-9769 \\ College of Education \\ University of South Africa \\ Pretoria, SOUTH AFRICA
}

Received: 18/05/2019 Accepted: 18/11/2019

\begin{abstract}
The transformation of higher education, in line with the South African Constitution, has led to increased enrolments of students with disabilities. However, limited research has been conducted on teaching and learning support these students receive. Access of students with disabilities in higher education is a human rights issue yet research shows that it has not been linked to increase in instructional support. As such, their participation has been limited. Some of the barriers limiting their participation are lecturers' negative attitudes due to lack of disability awareness and the unavailability or inadequacy of support in teaching and learning. As a result, higher education institutions have not succeeded in creating enabling teaching and learning environments for these students. This paper seeks to initiate discussion about the teaching and learning support needs of students with disabilities, particularly in an Open Distance e-Learning context and to propose strategies that can be employed to increase the quality of their participation and improve their academic outcomes.
\end{abstract}

Keywords: Students with disabilities; teaching and learning support; Open Distance e-Learning; higher education; access; participation.

\section{INTRODUCTION AND BACKGROUND}

The United Nations Convention on the Rights of Persons with Disabilities acknowledges and promotes equality for persons with disabilities (Rieser, 2018). The Convention calls on countries to foster an attitude of respect for the rights of people with disabilities at all levels of their education systems; develop inclusive education systems at all levels such that people with disabilities receive the support they require, and, promote programmes that raise awareness about people with disabilities and their rights (United Nations, 2006). All countries that are signatories to the UN recognise the needs and rights of students with disabilities in education and many have instituted legislation on how to integrate these students into all levels of education (Magnus, 2006).

When South Africa was welcomed back into the general Assembly of the United Nations in June 1994, it became bound by all resolutions taken at that level. As a result, the Constitution and all post-1994 education policies acknowledge access to education as a human right. As such, the transformation of the education system from being elitist and exclusionary to being inclusive has become a priority at both basic and higher education levels with the intention to improve access for all. However, the Convention on the Rights of Persons with Disabilities highlights that the inclusion and support of students with disabilities is still a global implementation challenge (United Nations, 2006). South Africa is also struggling to change attitudes and raise awareness about disability issues. This, in spite of research evidence which shows that education is a critical determinant of social mobility, and that higher education opens doors to better employment and quality of life (Magnus, 2006; Chataika, Mckenzie, Swart \& Lyner-Cleophas, 2014; Lyner-Cleophas, Swart, Chataika \& Bell, 2014). 
Since there is acknowledgement that education is critical in personal and economic development of communities, South Africa has to deal with the impact of past policies which pushed particular groups, including people with disabilities, to the margins of society (Department of Education, 1997a), thereby limiting their participation in all social spheres. After democracy, the South African Department of Education (hereafter DoE) (1997b) acknowledged that many children with disabilities were not benefiting from basic education either because they were refused admission to schools, or, if admitted, they were not given support to succeed in learning. Although there were special schools catering for different disabilities at that time, these were few and not available in marginalised communities (DoE, 2001). Consequently, very few young people with disabilities progressed to higher education. Even those who did, they struggled because the provision of necessary academic support to enable them to succeed was not a priority (Ntombela \& Subrayen, 2013).

In 1997, the Department of Education promulgated Education White Paper 3: A programme for the transformation of higher education (DoE, 1997a) with the objective to increase access to and participation of marginalised groups in higher education, including people with disabilities. Sixteen years later, the White Paper for Post-School Education and Training came out, a policy committing government to address post school barriers that limit the development of all students (Department of Higher Education and Training, 2013).

\section{CONCEPTUAL UNDERPINNINGS}

This discussion paper is guided by human rights and the philosophy of inclusion as conceptual frameworks. Education is a human right (UNESCO, 2001; RSA, 1996) and, according to the South African Constitution, the state is obliged to make further education available and accessible to everyone (RSA, 1996; DHET, 2013). The philosophy of inclusion promotes everyone's human right to education and challenges exclusionary practices and policies (Ntombela, 2013). This philosophy has been instrumental in influencing the transformation of education systems and societies in general as well as the development of policies that are inclusive (Ntombela, 2013).

In this paper, these two concepts are juxtaposed to highlight progress in transforming the education system as well as challenges that higher education faces in ensuring that all students admitted have support to participate meaningfully in all activities. Since access and participation are part of transformation, these concepts are an important lens in interrogating how higher education institutions (HEIs), particularly Open Distance e-Learning ones, can reach higher levels of student support to improve the participation of SWD and to uphold their right to education.

In the light of the developments highlighted above, this paper seeks to initiate discussion on the following issues:

a. How far has the South African higher education system progressed in addressing barriers that limit the development of students with disabilities (SWD)?

b. What issues affect access and participation of SWD in Open Distance e-Learning context?

c. What can be done to provide relevant teaching and learning support to SWD in higher education, particularly in ODeL contexts?

\section{Towards Addressing Barriers That Limit the Development of Students With Disabilities in South African Higher Education}

The adoption of the new South African Constitution promised all citizens equality before the Law and extended human rights to all (RSA, 1996). Similarly, the transformation of higher education in line with the Constitution and the promulgation of Education White Paper 3 (DoE, 1997a) has made it possible for those students previously marginalised to access higher education. The admission and participation of qualifying SWD in higher education is a basic human right protected in the Constitution (Department of Justice and Constitutional Development, 2016). This human right has got to be upheld because when students with and without disabilities enrol into HEIs, their admission has potential to empower them through increased 
knowledge base, exposure to debate and discussion, development of social skills and obtaining qualifications (Fuller, Bradley \& Healey, 2004). Teferra and Altbach (2004:21) also highlight that universities are leading in the field of knowledge and information production and that "higher education is recognised as a key force for modernization and development", in this century. This suggests that those who pursue university studies get empowered. It is in this vein that Wehman (2006) regards higher education as a means to improve people with disabilities' quality of life because it has potential to increase their employability, their earning power, and to give them independence. Therefore, it is important that as a country and as HEIs we do everything possible to support all students to have positive educational outcomes as this benefits them as well as the country.

In view of the benefits of higher education highlighted above, it is a cause for concern what Engelbrecht $\&$ de Beer (2014) highlight, that by 2010, enrolment statistics showed that only $0.8 \%$ of students in higher education institutions (HEIs) had indicated they had a disability. This low enrolment could be a confirmation of the influence of past policies, practices of marginalisation and discrimination that limited the participation of people with disabilities in education. The fact that by 2014 , "only $2.8 \%$ of disabled people have access..." at this level (Engelbrecht \& de Beer, 2014: 544), suggests that we have not been aggressive enough in addressing this matter. Although there had been some increase, it remains statistically insignificant when one considers that about $20 \%$ of young people with disabilities are enrolled in HEIs (South African Human Rights Commission, 2018). Furthermore, it also shows how critical it is for the country to intensify efforts to support young persons with disabilities to enrol and succeed in higher education.

A South African study also highlights that there are negative attitudes, curricular barriers, lack of appropriate services, poor resourcing and poor infrastructural design which act as barriers to learning, thus limiting the progress of SWD (Tugli et al, 2013). Other local studies confirm that there are still barriers to learning and development that limit the participation of these students at this level (Matshediso, 2007; Goode, 2007; Ntombela \& Subrayen, 2013; SAHRC, 2018). In another study exploring access challenges for students with visual disabilities at the University of KwaZulu-Natal, Ntombela and Soobrayen (2013) conclude that students' academic outcomes depend largely on staff's awareness, ability, and willingness to support all students. Similarly, Tugli, Zungu, Ramakuela, Goon and Anyawu (2013: 362) cite inadequacy of learning support materials and negative attitudes towards disability as major barriers to participation that perpetuate the exclusion of these students, impacting their "academic freedom and progress". In addition, Magnus (2006) and the SAHRC (2018) posit that lack of reasonable accommodations, lack of knowledge and general ignorance about disabilities are some of the key barriers that push these students to discontinue studying.

It seems that South Africa is not alone in fighting this access and participation battle that affects SWD. Moswela and Mukhopadhyay (2011: 308) maintain that in developed countries, there is research evidence that SWD still face "attitudinal, structural and resource-related" barriers as well as "curriculum delivery, alternative assessment" challenges which limit their progress and success. They report that things are no different in Southern Africa, as SWD face negative attitudes, teacher-centred teaching and learning processes, inflexible curriculum, inadequate assistive and instructional technologies (Moswela \& Mukhopadhyay, 2011:309).

Due to the paucity of support in higher education, fewer SWD progress to postgraduate studies. Such evidence confirms that the educational experiences of young persons with disabilities differ significantly from those of their peers without disabilities (RSA, 2016). This also confirms Nzimande's observation (2010) that large numbers of SWD take longer to graduate and that many drop out, a sentiment that was recently shared by Spassiani, Murchadha, Clince, et al, (2017). This is not surprising, though, if these students face so many challenges during their higher education years. However, these challenges need to be addressed as a matter of urgency because higher education is central to the transformation process. It has a responsibility to address inequalities that past policies and practices created (DoE, 1997a), which makes higher education important for all students, but more so for those with disabilities as it can provide opportunities to improve the quality of their lives.

What is evident though is that prejudice still prevails against SWD. This could explain why the Foundation of Tertiary Institutions of the Northern Metropolis (FOTIM) study (2011) found it difficult to get accurate statistics of registered SWD because many choose not to disclose their disability status. Taylor et al (nd) also 
found that students were not keen to disclose their status out of fear that their chances of admission could be negatively affected by this disclosure. The issue of non-disclosure is also highlighted by Kendall (2016) who highlights that students are sometimes reluctant to disclose their disability for fear that they may be viewed negatively or treated differently. This reluctance to disclose a disability could also work against them in that if there is no up-to-date information on the types of disabilities that institutions need to make provisions for, it can be difficult to plan and provide meaningful support (Kendall, 2016). Students could also be deprived reasonable accommodations that they qualify for simply because they have not declared an impairment. As such, the report that DHET is working on promoting the social inclusion of persons with disabilities in higher education (SAHRC, 2018) is welcomed, although such a move only addresses social access and not academic access and participation.

It appears that whilst many studies have been done on the experiences of SWD in contact institution, there seems to be much less known about the challenges of SWD studying through open distance e-Learning $(\mathrm{ODeL})$, a gap that this paper seeks to initiate discussion on. Non-contact institutions, by their very nature, will attract far more SWD than contact institutions. The question is, do their SWD fare better than those in contact institutions? Increasing access and participation is part of transformation and Ntombela and Mahlangu (2019) highlight how complex transforming a system is, arguing that increasing access without paying attention to participation does not bring about change in how institutions work. If indeed there are more SWD studying at a distance, how aware are those working there of the students' teaching and learning support needs? How critical are they of the dominant culture which informs programmes and services within the institution so that they do not perpetuate practices that keep SWD on the margins?

\section{Barriers to Access and Participation of SWD in an ODeL Context}

\section{Discourses Shaping our Provision of Teaching and Learning Opportunities for SWD}

Disability, according to the World Health Organization (1980: 14) is a result of "impairment in terms of functional performance and activity by an individual" whereas an impairment is an abnormality in the body structure or organ function. Although in everyday language the concepts are used interchangeably, a disability is a limitation that a person may experience socially due to the existence of an impairment. For example, deafness is an impairment but a deaf person experiences no disability in an environment where everyone is fluent in sign language and where videos have sub-titles. However, in a context where no one understands sign language they are totally disabled.

Since there is evidence that the universities are transforming and the number of SWD enrolled in higher education is increasing (Engelbrecht $\&$ de Beer, 2014), the question remains, what is informing this increase? This question is important because there could be different discourses influencing the admission of these students. If we do the right thing for the wrong reasons, the change we hope to see remains superficial and short-lived. We do not want transformation that is driven by the medical/deficit model which continues to dominate service provision in many parts of the country (Ntombela \& Soobrayen, 2013) even though the Constitution and policies developed post democracy have moved away from this model. The medical/ deficit model views disability just as an impairment and a limitation to participate (UNESCO, 2001) at the exclusion of the context. Within this model, admitting SWD is seen as a favour, as such, they are expected to find ways to fit in with very little support. Such an attitude continues to keep them on the periphery (Ntombela \& Soobrayen, 2013).

Then there is the social model which is promoted by the Constitution and all post democracy policies. This model emphasizes the 'disabling' and exclusionary impact of physical and social environments in the lives of people with disabilities (UNESCO, 2001; Ntombela \& Soobrayen, 2013). This is the model we need to embrace in our programmes and it should inform our support strategies as it forces us to scrutinise our beliefs and attitudes towards people with disabilities. In an ODeL context, it is very easy not to be aware of issues affecting SWD because the students may not be physically present at the institution, and therefore, remain invisible. Although this is changing rapidly at the University of South Africa, it is still the case for SWD. As such, it is very possible to remain immune to developments that challenge oppressive beliefs and practices, and academic and administrative staff could remain detached from disability advocacy debates and discussions. 


\section{Access and Participation as Two Sides of the Same Coin}

As the movement to increase the admission of SWD intensifies, we should look for strategies to increase their participation as well. This is necessary because increased access has no value unless linked to meaningful and quality participation and support (retention) strategies that lead to students' success. All students require various levels and forms of support to succeed in their learning, regardless of ability/disability and level of study, especially if they are studying at a distance. How, then, can an ODeL institution provide teaching and learning support that meets the needs of SWD? Currently there is minimal or no interaction between the disability unit (named the Advocacy and Resource Centre for Students with Disabilities) and academics, which leaves one wondering whose students are these. This unit is there to coordinate advocacy campaigns and motivate for resources. It is run by administrators who are not knowledgeable about the demands of the curriculum. Therefore, it is important for those responsible for teaching and learning to understand what support do the SWD need and, with the assistance of the unit, develop strategies that support teaching and learning for all.

Meaningful participation for SWD depends largely on academic support like curriculum delivery and alternate assessment procedures (Moswela \& Mukhopadhyay, 2011). However, it is worrisome to learn that university staff tends to lack awareness about disability policies and the support needs of SWD (FOTIM, 2011; Lyner-Cleophas et al 2014; SAHRC, 2018). The danger is that when staff is unable to provide support to these students, it increases their vulnerability, renders the students 'invisible' and susceptible to dropping out. Spassiani et al (2017) researching and writing with students with disabilities, also report that sometimes students with disabilities feel that students without disabilities receive preferential treatment. It is in this vein that Nzimande (2010) calls on universities to find relevant strategies to support these students and ensure that policies and practices do not exacerbate their vulnerability, a sentiment shared by Spassiani et al (2017).

Researching the experiences of SWD at an urban contact university, Ntombela and Soobrayen (2013) showed that systemic barriers (how things are organised and done) can reduce the level and quality of support available to these students. In another study based at a rural, contact university, Tugli et al (2013) investigated SWD' perceptions of access and support. They argue that poor resourcing and poor infrastructural designs negatively affect these students in as far as access, equity and support are concerned, and they concluded that increased access and support services are critical to enable SWD to participate equally in academic and social life (Tugli et al, 2006).

\section{Negative Attitudes}

Studies over the past decade have shed light on how SWD face negative attitudes in the higher education learning environment (Nzimande, 2010; Moswela \& Mukhopadhyay, 2011; Tugli et al, 2013; Engelbrecht $\&$ de Beer, 2014). Negative staff attitudes make these students feel judged and embarrassed (Spassiani et al (2017), and negatively impact their academic outcomes. It is a cause for concern what Tugli et al (2013:362) highlight, that students with disabilities felt that they were not welcome in the lecture halls and felt rejected by non-disabled students, staff and the institution. Then we wonder why many are reluctant to disclose their disability.

If SWD in contact institutions face all these challenges, how much more those studying at a distance where there is a real physical and emotional distance between them and their lecturers and the institution? When individual students request support and reasonable accommodations, how are those requests received? How soon do they get responses? Do lecturers understand the issue of accommodations? Just recently Unisa changed a parking block to parking for people with disabilities. Whilst we were surprised by that, we were even more surprised to see that those who had used those bays before they became designated bays are still using them now although they have no disabilities. This takes me back to the question I asked earlier, what is informing our transformation? Is it a matter of compliance or do we sincerely realise that how we operate can keep others on the margins?

The next sections attempts to explore possible solutions that can assist an ODeL institution to address these challenges. 


\title{
How Can We Remove or Reduce These Barriers in an ODeL Context?
}

\author{
Mainstreaming Disability at Institutional Level
}

Nzimande (2010) expressed concern that some of the barriers to learning experienced by SWD were linked to institutional culture and lack of sensitivity to their needs. So how can we re-culture our institution? Disability mainstreaming is a radical transformation approach to addressing issues facing persons with disabilities. It simply means placing disability at the centre of everything, making disability everyone's problem and concern. In a university context this means a review of "policies, budgets, plans and programmes" to ensure they respond to the needs of staff and students with disabilities (Republic of South Africa, 2016: 45). In ODeL context, unlike in contact institutions, it is difficult for SWD to mobilise or to engage the Student Representative Council about their issues, therefore, it is important that the institution is proactive and explore strategies that can be used to support all students, including those with disabilities. Having a unit that provides resources to SWD is not adequate as their main concerns are resource related whereas students are affected by lack of support in teaching and learning which limits their participation and affects their educational outcomes.

In his address, the then Minister of Higher Education, emphasized that issues affecting students with disabilities are cross-cutting (Nzimande, 2010). Implied is that institutions should seek to adopt cross-cutting strategies in addressing these issues. Cross-cutting strategies mean all stakeholders in higher education need to be appraised about issues of disabilities and how to remove barriers to participation.

However, a cause for concern highlighted by Matshedisho (2007:689) is the absence of policy 'compelling' academics in South Africa to support students with disabilities in their courses. He maintains that in many universities academic staff can choose whether to support or not support students with disabilities (Matshediso, 2007). How can staff have such a right when they have admitted these students? Besides, what makes SWD's needs for support different from those of other students? When those who teach are not aware of, or sensitive to, the learning needs of their students with disabilities, the students are disadvantaged and further disabled by the learning environment they find themselves in. Further, Tugli, Zungu, Ramuuela et al (2013) argue that when SWD are deprived of access and support, it leads to their social and academic exclusion.

The establishment of centres dedicated to supporting students with disabilities (Disability Units), in the case of Unisa, Advocasy and Resource Centre for Students with Disabilities (ARCSWiD), is an attempt to promote the inclusion of SWD. On the other hand, if the services of these units are not crosscutting and influencing the overall culture of institutions, then their presence could be reinforcing perceptions that issues of disability are not everybody's problem but should be handled by these offices only whilst for the rest of us it remains business as usual..

\section{Curriculum Transformation and Support}

Curriculum transformation in the form of programme design, format and methods of teaching is important as HEI respond to the support needs of SWD in the teaching and learning process (Nzimande, 2010). Engelbrecht and de Beer (2014) highlight that students with disabilities are often disempowered, and that they tend to struggle to find information about the availability of learning and assessment support. In a UK study, Sanderson (2001) cited in Taylor et al (n.d.) found that students with disabilities needed more specific information about what support is available to address their learning and assessment needs before deciding to enrol. This is important to note and very critical for an ODeL institution because of the distance between students and the institution.

It is also important to note what Taylor et al (n.d.) suggest, that lecturers need to be attentive to barriers that students with disabilities face when they develop assessment packages for their modules. Ntombela and Soobrayen's (2013) findings highlighted the need to provide staff development and support programmes on a regular basis. Similarly, Gertzel (2008:213) also emphasized the need to provide staff with professional development so that institutions develop "instructionally accessible environments". 
All this suggests a closer working relationship with ARCSWiD so that lecturers are aware of which students have special needs that require reasonable accommodations. Currently there is very little communication (if at all) between academic departments and ARCSWiD, which leaves SWD at the mercy of this unit in as far their support needs are concerned. The challenge with this is that lecturers do not get opportunities to understand and to explore how to support their students because someone else is taking this responsibility. It also delays the execution of support as students wait for lecturers to send information/documents then the students redirect it to ARCSWiD for conversion to appropriate format and then it is sent back to them.

\section{CONCLUSION}

The potential for empowerment that university study has for students is not always realised for SWD due to barriers to learning that they face (Fuller et al, 2004). What this discussion paper has attempted to highlight is that physical access does not mean epistemological access. SWD require accommodations/ support to benefit from teaching and learning processes. It is a good move that the ODeL institution has established a unit that is dedicated to providing support to SWD, it indicates commitment to address the needs of these students. Having a central place that students can go to for advice and support is good. However, the presence of this unit is also a problem that prevents the institution from fully transforming and placing disability at the centre. The disability coordinators end up being the only source of support for SWD whilst academics choose whether to render a service or not (Matshedisho, 2007). As long as there are people regarded as 'dedicated' staff employed to attend to the academic support needs of SWD, the rest of staff think they are free to carry on with their business as usual, or, if they do offer support, they might think they are doing these students a favour, that they are being benevolent. Therefore, the current support structure, ARCSWiD, cannot succeed in its function to support students if it works in isolation from the academics who have responsibility for the curriculum.

In conclusion, what this paper has shown is that although higher education has opened doors to SWD, the lives of these students have not changed much in spite of all that the Constitution and democratic policies promise. Their participation remains limited by the presence of a number of barriers to learning they experience in the system, even at an ODeL institution. The biggest barriers are negative attitudes, inadequate curriculum support due to lack of awareness on the part of faculty which negatively affect the ability of students with disabilities' to succeed in learning. When lecturers lack awareness about the (academic) needs of students with disabilities, it adds to the barriers the students already experience. The institutions also violate their human rights when they fail to provide students with quality education as enshrined in the Constitution. Without support from those who teach them, it is very difficult for many students with disabilities to participate meaningfully in higher education and to achieve positive outcomes. This means that staff development has to be prioritised to promote awareness and to ensure that there is adequate academic support to enable students with disabilities to participate fully in the teaching and learning process. This development should also target attitude change. Rieser (2018: 235) refers to this as teachers using a social model of "thinking about disabled people". When attitudes towards those who are different change, the scene is set for the transformation of how our communities view difference, including disability. Such transformation would also contribute towards building a human and social just society where no citizens remain on the margins. 


\section{BIODATA and CONTACT ADDRESSES of AUTHOR}

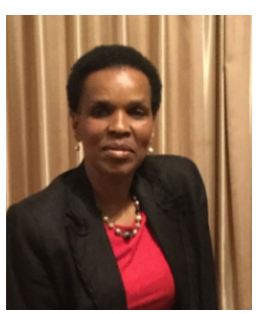

Dr. Sithabile NTOMBELA is an Associate Professor at the University of South Africa, College of Education, in the Department of Inclusive Education. She obtained her PhD in Education in 2007. She has extensive teaching experience in Educational Psychology and Inclusive Education at graduate and undergraduate teacher development levels. Her research focuses on how different sites of exclusion, particularly, disability, language and poverty, impact student outcomes. She has published over 15 journal articles in national and international indexes, 3 international book chapters as well as other national research outputs.

\section{Sithabile NTOMBELA}

Department of Inclusive Education, College of Education

University of South Africa, PO Box 392, Unisa, 0003, Pretoria, South Africa

Phone: +27 12 4812881,

E-mail: ntombs@unisa.ac.za

\section{REFERENCES}

Department of Education (South Africa) (1997a). Education White Paper 3: A Programme for Higher Education Transformation. Pretoria: Department of Education.

Department of Education (South Africa) (1997b). Quality education for all: Overcoming barriers to learning and development - Report of the National Commission on special needs in education and training (NCSNET) and National Committee on education support services (NCESS). Pretoria: Government Printers.

Department of Education. (2001). Education white paper 6: Special needs education - Building an inclusive education and training system. Pretoria: Government Printers

Department of Higher Education and Training (2013). White Paper on Post-School Education and Training. Government Printers: Pretoria.

Department of Justice and Constitutional Development (2016). The Basic Provisions of the Constitution of the Republic of South Africa, 1996, Made easy for learners. Pretoria: Department of Justice and Constitutional Development.

Engelbrecht, L. \& de Beer, J.J. (2014) Access constraints experienced by physically disabled students at a South African higher education institution. Africa Education Review, 11(4), 544-562.

Foundation of Tertiary Institutions of the Northern Metropolis (2011) Disability in higher education, Project Report. Massachusetts: Disability Management Services.

Fuller M, Bradley A and Healey M (2004) Incorporating disabled students within an inclusive higher education environment. Disability and Society, 19 (5), 455-468.

Getzel, E.E. (2008). Addressing the persistence and retention of studnets with disabilities in higher education: Incorporating key strategies and supports on campus. Exceptionality, 16(?), 207-219.

Kendall L 2016). Higher education and disability: Exploring student experiences. Cogent Education, 3 (?), 1256142, pp 1-12.

Lyner-Cleophas, M., Swart, E., Chataika, T., \& Bell, D. (2014) increasing access into higher education: insights from the 2011 African Network on Evidence-to-Action on Disability Symposium Education Commission. African Journal of Disabilities, 3 (2), Art.\#78, 3 pages

Magnus, E (2006) Disability and higher education: What are the barriers to participation? Paper presented at the Disability Studies Association Conference, September 18-20, Lancaster, UK. 
Matshedisho, KJ (2007) Access to higher education for disabled students in South Africa: A contradictory conjuncture of benevolence, rights and the social model of disability. Disability \& Society, 22(7), 685-699.

Moswela, E \& Mukhopadhyay, S (2011). Asking for too much? Voices of students with disabilities in Botswana. Disability \& Society, 26 (3), 307-319.

Ntombela, S (2013) Inclusive education and training in South African higher education: mapping the experiences of a student with physical disability at university. Africa Education Review, 10(2), 483501

Ntombela S \& Soobrayen R (2013) Access challenges for students with disabilities at the University of KwaZulu-Natal: A situational analysis of the Edgewood campus. Journal of Social Science, 37 (2), $149-155$.

Ntombela S \& Mahlangu VP (2019) The inclusion and support of students with disabilities in the South African higher education system. In R. Jeffries (ed.) Diversity, equity, and inclusivity in contemporary higher education (pp195-210). Hershey, United States of America: IGI Global.

Nzimande, B.B. (2010) Address by minister of higher education and training at the higher education disability service association (HEDSA) gala dinner, University of Free State. Accessed on 2010/10/14 from http://www.education.gov.za/dynamic.aspx?pageid=306\&id

Republic of South Africa (1996). The South African constitution. Pretoria: Government Printers

Republic of South Africa (2016) White paper on the rights of persons with disabilities. Gazette No. 39792. Pretoria: Government printers.

Rieser, R. (2018) Inclusive Education: implementing human rights. In M. Cole (ed.) Education, Equality and Human Rights: Issues of gender, race, sexuality, disability and social class. $4^{\text {th }}$ Edition. Routledge Taylor \& Francis Group: London. Pp230-266.

Seuring, S. \& Muller, M. (2008) From literature review to a conceptual framework for sustainable supply chain management. Journal of Cleaner Production, 16 (?), 1699-1710

Spassiani, N.A., Murchadha, N.O., Clince, M., Biddulph, K., Conradie, P., Costello, F., Cox, L., Daly, E., Daly, O., Middleton, C., McCabe, K., Philips, M., Soraghan, S., \&Tully, K. (2017). Likes, dislikes, supports and barriers: The experience of students with disabilities in university in Ireland. Disability \& Society, 32 (6), 892-912.

South Africa Human Rights Commission (2018). Research brief on disability \& equality in South Africa, 2013-2017. South African Human Rights Commission.

Taylor, G., Mellor, L. \& Walton, L. (n.d.). Students with disabilities and widening participation. http:// extra.shu.ac.uk/alac/comm_over.html, accessed 12 July 2017.

Teferra D and Altbach PG (2004) African higher education: Challenges for the $21^{\text {st }}$ century. Higher Education, 47, 21-50

Tugli AK, Zungu LI, Ramakuela NJ, Goon DT and Anyanwu FC (2013) Perceptions of students with disabilities concerning access and support in the learning environment of a rural-based university. African Journal for physical, Health Education, Recreation and Dance. Supplememnt 1:2, 356-364.

UNESCO, 2001. Open file on Inclusive Education: Support materials for managers and administrators. Paris: UNESCO

World Health Organization (1980) International Classification of Impairments, Disabilities, and Handicaps: A manual of classifications relating to the consequences of disease. Geneva: World Health Assembly. 